\title{
Crocodiles and grey nomads: A deadly combination?
}

Shelley Burgin ${ }^{1 *}$, Faculty of Society and Design, Bond University, Queensland, 4229, Australia. Phone: +61 75595 2189; Fax: +61 75595 1474: email:

sburgin@bond.edu.au

Nigel Hardiman², Business School, Top Education Institute, 1 Central Avenue, Eveleigh, New South Wales, 2015, Australia. Phone: +61 29209 4888; Fax: +61 2 9209 4887; email: nigelhardiman@gmail.com

*Corresponding author:

Emeritus Professor Shelley Burgin, Faculty of Society and Design, Bond University,

Gold Coast, Queensland, 4229, Australia. Phone: +61 75595 2189; Fax: +61 75595

1474: email: sburgin@bond.edu.au 
There are increasing numbers of active Australian retirees, many who wish to travel in retirement. While they are superficially similar to the American 'snowbirds', unlike snowbirds, these Australian 'grey nomads' tend to seek individual, extended, unstructured activities with short stays in remote, non-commercial locations. Their travel is predominantly by self-drive 4WD vehicle and they tow a caravan/campervan, and prefer remote bush camping sites or caravan parks to the commercial resorts that American snowbirds prefer. The northern clines of Australia are a popular destination for grey nomads who largely originate from the major cities. These cities are largely outside of the tropics where Australia's only large fierce animal, the estuarine or saltwater crocodile Crocodylus prosus inhabits. Successful crocodile conservation programs have substantially increased the numbers of this species throughout much of the coastal northern areas of Australia, the preferred destination of many grey nomads. We conclude that naïve grey nomads, encroaching into areas with increasing numbers of large crocodiles will result in increased attacks, and suggest that a strategic review of current conservation programs is required before public outcry for action against crocodile conservation efforts occurs.

Keywords retirees; Crocodylus porosus; wildlife conflict; wilderness recreation; Australian retirement trends; crocodile attack; self-drive holidays 


\section{Introduction - The issue}

Australia has an aging, population (Tate, Freeman, Mein \& Maguire, 2006; Higgs \& Quirk, 2007). Based on trends in 2000, it was projected that in economically developed countries by around 2015 , over $50.0 \%$ of a person's lifetime will be available for leisure (Molitor, 2000). This trend is driven by lower birth rates and greater longevity, and retirees are growing both in numbers and proportion of the total population (ABS, 2013). For example, Australians aged 65 ('retirement age') or over are projected to increase from 3.2 million (14.0\% of the population) in June 2012 to between 5.7-5.8 million (18.0-19.4\%) by 2031 (ABS, 2013), and the upward trajectory continues (Bolwellrv, 2014). However, available figures would be an underestimate of total retirees, as more Australians are choosing to retire before reaching 65 . For example, around $40.0 \%$ of Australians aged 45 years or over were retired in 2007 (ABS, 2009). Wolcott (1998) confirmed this trend. She found that there was a $72.0 \%$ participation in the work force among males between the ages of $55-59$, and $43.0 \%$ for women in this age bracket. The participation rate had dropped at 60-64 to $45.0 \%$ for men and $19.0 \%$ for women. These relatively wealthy, active retirees are the fastest growing segment of the tourism industry in Australia (Onyx \& Leonard, 2005).

Most of the Australian population is urban-based. The population is concentrated in coastal areas and $64.0 \%$ reside in the eight state/territory capital cities, seven of which are coastal (ABS, 2012) and only one, Darwin, is within the tropics. It is widely accepted that there is a disproportionate focus on aquatic resources compared to alternative outdoor recreational opportunities and water-based recreation is a choice of people of all ages (Burgin \& Hardiman, 2010; Hadwen, Arthington, Boon, Lepesteur \& McComb, 2006). Such aquatic resources in Australia's tropics are 
inhabited by the saltwater crocodile Crocodylus porosus, whose populations in both number and size of animals have increased dramatically in recent years owing to legal protection and conservation programmes (e.g., Webb, Britton, Manolis, Ottley \& Stirrat, 2000).

In this paper we will explore the emerging trends of the penchant of a growing number of Australian retirees to seek new experiences, often in the tropical north of the country and thus exposing them to an increased risk of crocodile attack. We (i) review the emergence of the Australian 'grey nomad' tourism phenomenon; (ii) consider the associated potential for conflict between human safety and crocodile conservation; and (iii) suggest future social and ecological research priorities and/or management implications.

\section{Grey nomads}

Australian 'grey nomads', are typically retired men and women who travel independently (e.g., by caravan, motorhome or campervan) for extended periods around the island continent, typically from 3 months to several years. They 'follow the sun' and their own itinerary with the changing seasons (Onyx \& Leonard, 2005, 2007). They are not time-constrained and their trip represents a lifestyle rather than a holiday. Such a lifestyle does not conform to social expectations enshrined in the traditional 'rise and fall' model of human ageing by which an individual's physical and cognitive abilities grow through childhood and young adulthood, mature in middle age and subsequently decline thereafter (Leonard \& Burns, 2001). This emerging lifestyle choice has been described as an 'Ulyssean' approach to ageing, by which individuals actively pursue personal choice and seek new experiences in later 
life (Onyx \& Leonard, 2007), and has the potential for challenging many aspects of medical and social planning (Higgs \& Quirk, 2007; Tate et al., 2006).

Not all retirees seek the same experience. Various studies in Australia and internationally have identified different consumer segments, each with differing needs and motivations. Examples include 'escapists and learners', 'retirees' and 'active storytellers' among Americans (Shoemaker, 2000) and 'nostalgics', 'friendlies', 'learners' and 'escapists' among Australians (Cleaver, Muller, Ruys \& Wei, 1999). In some respects, Australian 'grey nomads' are similar to American 'snowbirds'. Snowbirds are seasonal migrants from cooler states of the Northern United States of America (US) and Canada who over-winter, typically at recreational vehicle resorts, in the warmer Southern US states, especially in Florida (Happel \& Hogan, 2002; Smith \& House, 2006). While sharing some superficial similarities; however, there appear to be substantial differences between Australian grey nomads and Northern American snowbirds. Snowbirds appear to be gregarious, seek structured recreational activities and stay the whole trip at a single, commercial resort. In contrast, although grey nomads do enjoy social networking with other travellers, they appear to place greater value on individual, unstructured activities and make relatively short stays in remote, non-commercial locations as part of an overall 'journey'. They travel predominantly by self-drive $4 \mathrm{WD}$ vehicle, tow a caravan/campervan and prefer a mixture of remote bush camping and caravan park sites over commercial resorts (Onyx \& Leonard, 2005, 2007).

While definitions differ between studies, and accurate quantification is problematic, approximately $22.0 \%$ of those over 45 years who are retired or semiretired and have no children at home, or $20.0 \%$ of all Australian domestic overnight leisure visitors may be classified as grey nomads (TRA, 2007). This percentage of 
travellers may be considerably higher in some destinations and/or mode of travel. For example, in Western Australia, grey nomads comprise $40.0 \%$ of visitors to caravan parks (TWATRA, 2007). The majority originate from Queensland (30.0\%), Victoria (26.0\%) and New South Wales (18.0\%). The mean trip length was identified to be 212 nights, with an average of 104 nights spent in Western Australia. There is some indirect evidence of a winter south to north migration (Pearce, 1999) and a tendency to travel counter-clockwise around the country (TWATRA, 2007). The northern states of Queensland, Northern Territory and Western Australia are especially popular among grey nomads as they offer opportunities for sought experiences such as freedom, independence and adventure in remote wilderness (Onyx \& Leonard, 2005, 2007). All three states have low resident populations, highly concentrated in their respective capital city and each receives relatively high numbers of domestic visitors annually (Table 1).

\section{Dangers of outdoor recreation}

Most recreation outside of the tropics presents limited danger from Australian native wildlife. While there are a wide range of venomous animals, bites occur infrequently and deaths are rare (White, 1995, 1998; White, Pounder, Pearn \& Morrison, 1985). Although snakes are the most common cause of such human fatalities (White, 2000), the number of deaths has been declining annually in recent decades (Currie, 2004; Mirtschin, Masci, Paton \& Kuchel, 1998; Sutherland \& Leonard, 1995). Arthropod bites (e.g., spiders, ants, centipedes), although medically significant, seldom result in death. There are also substantial numbers of marine invertebrates that are venomous or poisonous, including jellyfish (e.g., box jellyfish Chironex fleckeri), stinging fish, blue ringed octopus (Hapalochlaene spp.) while seas snakes are also venomous 
(White, 1998). Shark attacks, although widely publicised and frequently fatal, are actually rare since throughout the last two centuries less than one person has been killed annually by such attacks in Australia (Caldicott, Mahajani \& Kuhn, 2001). Among terrestrial vertebrates there have been two deaths due to attack from semidomesticated dingos (Ayers Rock [Uluru] - Marcus, 1989; Fraser Island - Peace 2002), and there have been several recorded non-lethal attacks (Peace, 2002; Cartwright, 2011, Crawford, 2012). Outside of the tropics, there are no vertebrates that have the potential to attack and kill adult humans. Most Australians are, therefore, not confronted with the issues associated with dealing with large, wild and dangerous animals. Within the tropics; however, the saltwater crocodile Crocodylus porosus is increasingly becoming the exception.

\section{Australian crocodiles}

Two crocodile species inhabit Australian waters; the saltwater or estuarine crocodile and the freshwater crocodile Crocodylus johnstoni. Both species have a range that includes much of Northern Australia; Queensland, the Northern Territory and Western Australia, encroaching only marginally below the Tropic of Capricorn in coastal Queensland and Western Australia. While both species are concentrated in coastal areas, they may disperse considerable distances inland during wet season flooding. Where it occurs, the saltwater crocodile is a keystone species with the only other saltwater crocodiles and humans as potential enemies. Historically, populations have been limited naturally only by available food and habitat (Webb \& Manolis, 1998).

Although attacks on humans by freshwater crocodiles have been recorded (e.g., Caldicott, Croser, Manolis, Webb \& Britton, 2005; Lindner, 2004), this species 
has a diet made up largely of fish and crustaceans (Webb \& Manolis, 1993) and is generally regarded as being inoffensive unless provoked, for example when protecting eggs or hatchlings. In contrast, the saltwater crocodile has been implicated in unprovoked attacks on humans involving injury or death, both in Australia and elsewhere within its South-east Asian range (Caldicott et al., 2005). This crocodile is one of the largest of its kind in the world and has a predilection for hunting humans (Burgin, 1981). Despite its common names (saltwater, marine) implying that it is associated with the mouths of rivers and beyond, it may be found anywhere in a river system, including swamps, billabongs, and headwater habitat provided there is sufficient water (Burgin, 1981; CSG, 1996). Their Australian habitat, north of the Tropic of Capricorn (Webb \& Manolis, 1993), is the least populated by humans (ABS, 2012) but increasingly popular with grey nomads (Onyx \& Leonard, 2005). Saltwater crocodiles are ambush predators and may lie submerged in wait for prey for two to three hours before launching an explosive attack. Despite their large size and weight, they are capable of moving fast over short distances, even on land. In water they are extremely agile and capable of leaping their own body length vertically above the surface. Their jaws are powerful, capable of crushing turtle shells and pig skulls, with biting force proportional to crocodile size. Small prey is swallowed whole, while large prey is broken up by head whipping and/or violent body rolling (Caldicott et al., 2005).

As in Papua New Guinea (Burgin, 1981), crocodiles have been hunted in Australia by aborigines for their food and livelihood during the last 2,000 years and animals and eggs continue to be collected. While their impact on crocodile populations is unknown, aborigines are skilled hunters, may know the position of all nesting sites within an area, and do kill the female guarding the nest and remove her 
eggs. In heavily hunted areas, freshwater crocodiles are wary of humans (Webb \& Manolis, 1993). However, the landscape is now 'very sparsely populated' outside of urban centres (Yibarbuk, Whitehead, Russell-Smith, Jackson, Godjuwa, Fisher, Cooke, Choquenot \& Bowman, 2001). Presumably, this has reduced pressure on crocodile populations and wariness of humans would become less intense over time.

Europeans settled Northern Australia during the first half of the 1800s. Crocodiles were apparently widespread, sometimes abundant but patchy in distribution. With the establishment of the cattle industry saltwater crocodiles were treated as vermin (Webb \& Manolis, 1993) although since most crocodile habitat tends to be at the mouth of the rivers in areas of mangroves and swamps, and without the convenience of modern equipment, the overall impact on the population was probably not substantial. Crocodile numbers may even have increased following European settlement as aborigines began to congregate around settlements and spent less time in traditional hunting (Webb, Messel, Crawford \& Yerbury, 1987).

Although there were some isolated attempts to develop a commercial skin trade in the early 1900s (Cole, 1992), 'serious commercial crocodile hunting' targeting saltwater crocodiles commenced after World War II. Between 1946 and 1960 the rivers of Northern Australia were systematically and efficiently hunted until large crocodiles became scarce across the whole region. Populations in wetlands closest to settlements were most heavily hunted and, in addition to hunting for skins, crocodile hatchings and small juveniles were also collected for the curio trade. By the end of the 1960s, populations had dwindled, there were few professional fulltime hunters and the few remaining large animals had become increasingly wary of humans (Webb \& Manolis, 1993). 
As a result of such impacts, saltwater crocodiles became protected in Western Australia in 1969 (C. Johnstoni, 1962), the Northern Territory in 1971 (C. Johnstoni, 1964), and in Queensland in 1974 (C. Johnstoni, 1974) (Letts, 2004). Additional protective legislation was provided by the Federal Government's Environmental Protection and Biodiversity Conservation Act 1999, and they remain on Appendix II of the IUCN Red List of Threatened Species (CSG, 1996). This protection has provided the basis for recovery (Stirrat, Lawson, Freeland \& Morton, 2001).

By the 2000s, saltwater crocodile populations across their Australian range (Western Australia - CALM, 2003, Northern Territory - Webb et al., 2000;

Queensland - Read, Miller, Bell \& Felton, 2004) had greatly increased (Webb et al., 2000), reflected in their change in status from Appendix I to Appendix II (Caldicott et al., 2005). Saltwater crocodiles in the Northern Territory increased from an estimated 3,000 to 5,000 in 1971, to more than 75,000 non-hatchlings in 2004 (Letnic, 2004) and Queensland's non-hatchling population was estimated to be approximately 4,300 in 2004 (Read et al., 2004). In Western Australia, while there have been no recent state-wide surveys, it was estimated that in 1986 there were approximately 2,500 nonhatchling crocodiles in the Kimberley region alone (Mawson, 2004). The increase in saltwater crocodile populations has also been marked by an associated growth in average animal size (Webb, et al., 2000).

Internationally, evidence suggests that successful conservation and management regimes that have led to increased populations have been paralleled with increases in crocodile attacks on humans (Caldicott et al., 2005). For example, Andau, Ambu \& Tsubouchi (2004) concluded that increased crocodile numbers have resulted in greater numbers of attacks on humans in Sabah and Malaysia, while Glasgow (1991) suggested that a combination of increased numbers of American alligators and 
a parallel expansion of the human population in Louisiana during the 1970s resulted in increased confrontations between humans and alligators. In northern Australia between 1971 and 2004 there has also been an increased frequency of crocodile attacks on humans (Caldicott et al., 2005, Table 2).

Factors that increase confrontations between humans and crocodiles include increased human populations, development of the crocodile's habitat, and increased popularity of water-based recreational activities (Caldicott et al., 2005). As indicated above, the successful crocodile recovery program in Australia has resulted in an increasingly large population of crocodiles of increased size associated with reduced levels of wariness of humans because they have not been exposed to intense hunting pressure for over three decades (Webb et al., 2000). Females reach sexual maturity at approximately 12 to 14 years old (approximately 2.2-2.4 m), and males at around 16 years (approximately 3.0-3.6 m) and they continue to grow to $7 \mathrm{~m}$ (Webb, Messel, Crawford \& Yerbury, 1978, 1978). Fatal attacks are generally by large (> $4 \mathrm{~m}$ long) male crocodiles (Caldicott et al., 2005). There are therefore likely to be a large number of large crocodiles that have not learned to be wary of humans.

\section{Clash between grey nomads and crocodiles}

This increase in the number of large crocodiles across Northern Australia has been paralleled with the growing numbers of grey nomads in the area, originating from the southern half of the continent (i.e., outside of the range of crocodiles).

While not as low as shark attacks (i.e., an average of 1.1 annually for the 20 years to 2011, West, 2011) but with a moderate increase subsequently (McPhee, 2014), crocodile attacks in Australia have remained relatively rare (Table 3). However, while there appears to have been a general decline in shark populations 
(e.g., Baum, Myers, Kehler, Worm, Harley \& Doherty, 2003, 2004; Heithaus, Wirsing, Dill \& Heithaus, 2007; Robbins, Hisano, Connolly \& Choat, 2006), the trend for increasing numbers of large crocodiles over the last two decades is the reverse, and they are less wary of humans than pre-protection populations (Webb et al., 2000). In parallel, the numbers of grey nomads without experience of potentially dangerous animals but seeking the solitude of wilderness are increasing (Onyx \& Leonard, 2005) and there has been an upward trend in crocodile attacks from 0.5 annually between 1971 and 1980 to 2.9 annually between 2001 and 2010, with a rise to 3.25 post 2010 (Table 2). Without intervention, it can be assumed that the increasing numbers of crocodiles and grey nomads will continue. This will increase the likelihood of each to encroach on the 'territory' of the other and thus the risk of attacks will become more acute.

In New South Wales and Queensland, the main response to the threat of shark attack on humans has been the long-term and deliberate attempt to reduce their numbers through gill netting, in Queensland supplemented with baited drumlines (Dudley, 1997). In addition to impacting the target species; however, large numbers of non-target species, including protected species of other sharks, cetaceans, fish and marine invertebrates also continue to perish annually in such nets (Hardiman \& Burgin, 2010). An increase in crocodile attacks will undoubtedly elicit a community outcry for their control, and in some quarters probably eradication.

\section{Conclusion and recommendations}

Crocodile conservation efforts in Australia have been a resounding success (Hutton, Ross \& Webb, 2001). However, along with every silver lining comes a cloud. With increasing numbers of grey nomads encroaching on the territories of increasing 
numbers of large crocodiles, without additional action by land management agencies it is highly probable that the number of crocodile attacks on humans resulting in serious injury or death will increase and ultimately there will be community demand for action, most likely the permitting of commercial hunting and/or increased culling of the species. To avoid the need to react to such disquiet, we suggest that strategically there is a need for immediate action. This is because the most successful conservation programs for crocodiles have been based on broad input during the preparation and implementation that accounted for the prevailing socio-economic environment (Hutton et al., 2001). A review of the current approach to crocodile management in Australia would therefore be best achieved before community emotions were inflamed by escalating numbers of crocodile attacks. There is, therefore, a need for (i) social research on travel patterns and/or knowledge of crocodile danger among grey nomads; (ii) better publication and encouragement of people to report non-fatal attacks [only fatal attacks tend to get reported]; (iii) more investment to allow better shared database knowledge of crocodile attacks across the three northern states, similar to shark databases; and (iv) increased education targeted specifically at the grey nomad tourist.

\section{References}

ABS. (2013). 3222.0 - Population projections, Australia 2012 (base) to 2101.

Australian Bureau of Statistics, Canberra. Retrieved from http://www.abs.gov.au/ausstats/abs@.nsf/Lookup/3222.0main+features52012 $\% 20$ (base)\%20to\%202101.

ABS. (2014). Australian social trends, March 2009. Cat. 4102.0. Australian Bureau of Statistics. Retrieved from http://www.abs.gov.au/AUSSTATS/abs@.nsf/DetailsPage/4102.0March\%202 009? OpenDocument. 
Andau, P., Ambu, L., \& Tsubouchi, T. (2004). Indication of crocodile recovery and management implications in crocodile conservation in Sabah. In Crocodiles: Proceedings of the 17th Working Meeting of the Crocodile Specialist Group (pp. 204-207). Gland: International Union for the Conservation of Nature.

Baum, J. K., \& Myers, R. A. (2004). Shifting baselines and the decline of pelagic sharks in the Gulf of Mexico. Ecological Letters, 7, 135-145.

Baum, J. K., Myers, R. A., Kehler, D. G., Worm, B., Harley, S. J., \& Doherty, P. A. (2003). Collapse and conservation of shark populations in the Northwest Atlantic. Science, 299, 389-392

Bolwellrv (2014). The power of the grey dollar: The economic effect of grey nomads on regional economies. Retrieved from http://bolwellrv.com.au/caravanninglifestyle/the-power-of-the-grey-dollar-the-economic-effect-of-grey-nomadson-regional-economies.

Burgin, S. (1981). The biology and ecology of Crocodylus porosus (Schneider), Science in New Guinea, 8, 9-37.

Burgin, S., \& Hardiman, N. (2011). The direct physical, chemical and biotic impacts on Australian coastal waters due to recreational boating. Biodiversity and Conservation, 20, 683-701.

Caldicott, G. E., Croser, D., Manolis, C., Webb, G., \& Britton, A. (2005). Crocodile attack in Australia: An analysis of its incidence and review of the pathology and management of crocodilian attacks in general. Wilderness and Environmental Medicine, 16, 143-159.

Caldicott, D. G. E., Mahajani, R., \& Kuhn, M. (2001). The anatomy of a shark attack: a case report and review of the literature. Injury, 32, 445-453.

CALM. (2003). Saltwater crocodile (Crocodylus porosus) and freshwater crocodile (Crocodylus johnstoni) Management Plan for Western Australia 2004-2008. Perth: Department of Conservation and Land Management.

Cartwright, D. (2011). Dingo attack on girl could have been worse. Brisbane Times. Retrieved from http://www.brisbanetimes.com.au/environment/animals/dingoattack-on-girl-could-have-been-worse-20110426-1duyb.html

Cleaver, M., Muller, T., Ruys, H., \& Wei, S. (1999). Tourism product development for the senior market, based on travel-motive research. Tourism Recreation Research, 24, 5-11.

Cole, T. (1992). Crocodiles and other characters. Sydney, Australia: Pan Macmillan. 
Crawford, S. (2012). Dingo drags teen girl. NT News, Retrieved from http://www.ntnews.com.au/

Crockett, G. (2011). Australian crocodile attacks - Australia (Crocodylus porosus). Retrieved from http://saltwatercrocodiles.homestead.com/index.html.

CSG. (1996). Crocodylus porosus. In: 2007 IUCN Red List of Threatened Species. Crocodile Specialist Group. Retrieved from http://www.iucnredlist.org/search/details.php/5668/summ.

Currie, B. J. (2004). Snakebite in tropical Australia: a prospective study in the "Top End" of the Northern Territory. Medical Journal of Australia, 181, 693-697.

Dudley, S. F. J. (1997). A comparison of the shark control programs of New South Wales and Queensland (Australia) and KwaZulu-Natal (South Africa). Ocean and Coastal Management, 34, 1-27.

Glasgow, V. L. (1991). A social history of the American alligator. New York, United States of America: St Martins Press.

Hadwen, W. L., Arthington, A. H., Boon, P. I., Lepesteur, M., \& McComb, A. (2006). Rivers, streams, lakes and estuaries: hot spots for cool recreation and tourism in Australia. Technical Report Series. Gold Coast: Cooperative Research Centre for Sustainable Tourism Pty Ltd.

Happel, S.K., \& Hogan, T.D. (2002). Counting snowbirds: The importance of and the problems with estimating seasonal populations. Population Research and Policy Review, 21, 227-240.

Hardiman, N. \& Burgin, S. (2010). Recreational impacts on the fauna of Australian coastal marine ecosystems Journal of Environmental Management, 91, 20962108. Heithaus, M. R., Wirsing, A. J., Dill, L. D., \& Heithaus, L. I. (2007). Long-term momvements of tiger sharks satellite-tagged in Shark Bay, Western Australia. Marine Biology, 151, 1455-1461.

Higgs, P. F. D., \& Quirk, F. (2007). "Grey Nomads" in Australia: are they a good model for successful aging and health? Annals of the New York Academy of Sciences, 1114, 251-257.

Hutton, J., Ross, P., \& Webb, G. (2001). Using the market to create incentives for the conservation of crocodiles: a review. Gland: Species Survival Commission Crocodile Specialist Group.

Langley, R. L. (2005). Alligator attacks on humans in the United States. Wilderness \& Environmental Medicine, 16, 119-124. 
Leonard, R., \& Burns, A. (2001). Models of the life-span for an ageing society. In J. R. Morss, N. Stephenson, \& H. Van Rappard (Eds.), Theoretical issues in psychology (pp. 265-274). Boston: Kluwer Press.

Letnic, M. (2004). Crocodile management in the Northern Territory of Australia. In Crocodiles: Proceedings of the 17th Working Meeting of the Crocodile Specialist Group, 4-12. (Gland: International Union for the Conservation of Nature).

Letts, G. (2004). The history of crocodile conservation in Australia. In Crocodiles: Proceedings of the 17th Working Meeting of the Crocodile Specialist Group. (pp. 1-3) Gland: International Union for the Conservation of Nature.

Lindner, G. (2004). Crocodile management - Kakadu National Park. In Crocodiles. Proceedings of the $17^{\text {th }}$ Working Meeting of the IUCN-SSC Crocodile Specialist Group. (pp. 41-51). Gland: International Union for the Conservation of Nature.

Marcus, J. (1989). Prisoner of discourse: the dingo, the dog and the baby. Anthropology Today, 5, 15-19.

Mawson, P. R. (2004). Crocodile management in Western Australia. In: Crocodiles: Proceedings of the 17th Working Meeting of the Crocodile Specialist Group (pp. 28-37). Gland: International Union for the Conservation of Nature.

McPhee, D. (2014). Unprovoked shark bites: are they becoming more prevalent? Coastal Management, 42, 478-492.

Mirtschin, P. J., Masci, P., Paton, D. C., \& Kuchel, T. (1998). Snake bites recorded by veterinary practices in Australia. Australian Veterinary Journal, 76, 195-198.

Molitor, G. T. T. (2000). Five activities likely to dominate the new millennium: II The leisure era. Technological Forecast of Social Change, 65, 239-249.

Onyx, J., \& Leonard, R. (2005). Australian grey nomads and American snowbirds: similarities and differences. The Journal of Tourism Studies, 16, 61-68.

Onyx, J., \& Leonard, R. (2007). The Grey Nomad phenomenon: changing the script of aging. Journal of Aging and Human Development, 64, 381-398.

Peace, A. (2002). Dingoes, development and death in an Australian tourist location. Anthropology Today 18, 14-19.

Read, M. A., Miller, J. D., Bell, I. P., \& Felton, A. (2004). The distribution and abundance of the estuarine crocodile, Crocodylus porosus, in Queensland. Wildlife Research, 31, 527-534. 
Robbins, W. D., Hisano, M., Connolly, S. R., \& Choat, H. (2006). Ongoing collapse of coral-reef shark populations. Current Biology, 16, 2314-2319.

Shoemaker, S. (2000). Segmenting the mature market: 10 years later. Journal of Travel Research, 39, 11-26.

Smith, S. K., \& House, M. (2006). Snowbirds, sunbirds, and stayers: Seasonal migration of elderly adults in Florida. Journal of Gerontology, 61B, S232S239.

Stirrat, S. C., Lawson, D., Freeland, W. J., \& Morton, R. (2001). Monitoring Crocodylus porosus populations in the Northern Territory of Australia: a retrospective power analysis. Wildlife Research, 28, 547-554.

Sutherland, S. K., \& Leonard, R. L. (1995). Snakebite deaths in Australia 1992-1994 and a management update. Medical Journal of Australia, 163, 616-618.

Tate, J., Mein, J., Freeman, H., \& Maguire, G. (2006). Grey nomads: health and health preparation of older travellers in remote Australia. Australian Family Physician, 35, 70-72.

TRA. (2007). Changing consumer behaviour: Impact on the Australian domestic tourism market, February 2007. Canberra: Tourism Research Australia.

TWATRA. (2007). Understanding the caravan park industry in WA. Perth: Tourism Western Australia and Tourism Research Australia.

Webb, G. J. W., Britton, A. R. C., Manolis, S. C., Ottley, B., \& Stirrat, S. (2000). The recovery of Crocodylus porosus in the Northern Territory of Australia: 19711998. In Crocodiles: Proceedings of the $15^{\text {th }}$ Working Meeting of the IUCNSSC Crocodile Specialist Group, Varadero, Cuba (pp. 196-235). Gland: International Union for the Conservation of Nature.

Webb, G. J. W., \& Manolis, S. C. (1993). Crocodiles of Australia. Chatswood: New Holland.

Webb, G. J. W., Messel, H., Crawford, H., \& Yerbury, M. J. (1978). Growth rates of Crocodylus porosus (Reptilia: Crocodilia) from Arnhem Land, Northern Australia. Australian Journal of Wildlife Research, 5, 385-399.

Webb, G. J. W., Whitehead, P. J., \& Manolis, S. C. (1987). Crocodile management in the Northern Territory of Australia. In G. J. W. Webb, S. C. Manolis, \& P. J. Whitehead (Eds.), Wildlife management: Crocodiles and alligators (pp. 107124). Chipping Norton: Surrey Beatty and Sons. 
West, J. G. (2011). Changing patterns of shark attacks in Australian waters. Marine and Freshwater Research, 62, 744-754.

White, J. (1995). Clinical toxicology of snakebite in Australia and New Guinea. In: J. Meier, \& J. White (Eds.), Handbook of clinical toxicology of animal venoms and poisons. Boca Raton: CRC Press.

White, J. (1998). Envenoming and antivenom use in Australia. Toxicon, 36, 14831492.

White, J. (2000). Bites and stings from venomous animals: a global overview. Therapeutic drug monitoring, 22, 65-68. White, J., Pounder, D., Pearn, J. H., \& Morrison, J. J. (1985). A perspective on the problems of snakebite in Australia. In: G. Grigg, R. Shine, \& H. Ehmann (Eds.), Biology of Australasian Frogs and Reptiles (pp. 511-514). Chipping Norton, Australia: Surrey Beatty and Sons.

Wolcott, I. (1998). Families in later life: Dimensions of retirement. Australian Institute of Family Studies, Working Paper No. 14. Retrieved from http://www.aifs.gov.au/institute/pubs/wolcott1.html.

Yibarbuk, D., Whitehead, P. J., Russell-Smith, J., Jackson, D., Godjuwa, C., Fisher, A., Cooke, P., Choquenot, D., \& Bowman, D. M. J. (2001). Fire ecology and Aboriginal land management in central Arnhem Land, northern Australia: a tradition of ecosystem management. Journal of Biogeography, 28, 325-343. 
Table 1: Northern Australian state populations for 2007 (source ABS, 2012) and 2008-2009 domestic overnight visitor nights (TRA, 2010 a, b, c, d, e, f).

\begin{tabular}{lccc}
\hline State/Region & Region \% share of & $\%$ share of region & $\%$ share of region \\
state domestic & domestic overnight & domestic visitor \\
overnight visitors & visitors by retirees & nights by retirees
\end{tabular}

${ }^{1}$ Queensland

Outside of crocodile range

Gold Coast

Brisbane

Sunshine Coast

${ }^{2}$ Hervey Bay

Darling Downs

Bundaberg

Outback

Inside crocodile range

Fitzroy

Mackay

Whitsundays

Northern

Tropical

Total State

${ }^{3}$ Northern Territory

Outside of crocodile range
19.7

28.8

14.3

6.9

6.5

3.4

3.2

5.8

3.6

2.5

5.3

9.3

100

17.0

18.3

15.0

28.8

19.4

24.8

24.3

19.0

14.9

19.7

20.5
23 27

23

43

49 30 37 20

28

$17.5 \quad 24$

MacDonnell

6.0

na

$\mathrm{Na}$ 
Petermann

Alice Springs

Tablelands

Within the crocodile range

Darwin

Kakadu

Arnhem

Katherine

Daly

Total state

${ }^{4}$ Western Australia

Outside of crocodile range

30.6

17.2 22

Perth

48.4

11.9

100.0

15.9

23

Outback

Total state

Inside crocodile range

Coral Coast

8.6

23.8

40

North West

8.3

18.6

28

31

na
34

na

45

na

32

$20.1 \quad 25$

$16.1 \quad 26$ 
${ }^{3}$ Northern Territory residents $-215,000$ (capital - 117,000); Domestic overnight visitors $-1,072(600)$

${ }^{4}$ Western Australia residents - 2,106,000 (capital - 1,554,000); Domestic overnight visitors $-5,514(2,670)$ 
Table 2: Mean number of saltwater crocodile attacks per year in the Northern Territory and Australia 1971-2010

$\begin{array}{lll}\text { Period } & \text { Fatal Non-Fatal Total }\end{array}$

Northern Territory

\begin{tabular}{lccc}
\hline $1971-1980$ & 0.2 & 0.0 & 0.2 \\
$1981-1990$ & 0.4 & 1.0 & 1.4 \\
$1991-2000$ & 0.2 & 1.2 & 1.4 \\
$2001-2010$ & 0.7 & 1.2 & 1.9 \\
$2011-2014$ & 1.25 & 1.25 & 2.50 \\
\hline
\end{tabular}

Australia overall

\begin{tabular}{lccc}
$1971-1980$ & 0.4 & 0.1 & 0.5 \\
$1981-1990$ & 0.8 & 1.2 & 2.0 \\
$1991-2000$ & 0.3 & 1.9 & 2.2 \\
$2001-2010$ & 1.0 & 1.9 & 2.9 \\
$2011-2014$ & 1.25 & 2.0 & 3.25 \\
\hline
\end{tabular}

Source: 1971-2004 - Caldicott et al., 2005; 2005-2010 - collated by authors from reports of the Crocodile Specialist Group, Sydney Morning Herald and Australian 
Broadcasting Corporation; 2011-2014 - collated by authors and confirmed by Crockett, 2011 
Table 3: Number (percent of all attacks) of saltwater crocodile attacks in the wild in northern Australia 1971-2014

Number (percent) of all attacks

\begin{tabular}{llccc} 
Attack type & Northern & Queensland & Western & All states \\
& Territory & & Australia & \\
& & & & \\
& & & & \\
Fatal & $20(33.9)$ & $8(38.1)$ & $2(18.2)$ & \\
Non-Fatal & $39(66.1)$ & $13(61.9)$ & $11(81.8)$ & $63(67.7)$ \\
& & & & \\
Total & $59(63.4)$ & $21(22.6)$ & $13(14.0)$ & $93(100.0)$ \\
\hline
\end{tabular}

Source: 1971-2004 - Caldicott et al., 2005; 2005-2010 - collated by authors from reports of the Crocodile Specialist Group, Sydney Morning Herald and Australian Broadcasting Corporation; 2011-2014 - collated by authors and confirmed by Crockett, 2011 